\title{
Preparation of Biphenyl Array using Aryl Sulfide as a Safety Catch Linker for Solid Phase Organic Synthesis
}

\author{
Osamu Shimomura ${ }^{1}$, Kosuke Tayama ${ }^{1}$, Kazutaka Maeta ${ }^{1}$, and Ryôki Nomura ${ }^{1,2}$ \\ ${ }^{1}$ Department of Applied Chemistry and ${ }^{2}$ NMRC, Osaka Institute of Technology \\ 5-16-1, Ô-miya, Asahi-ku, Osaka, 535-8585 Japan \\ FAX: +81-6-6954-4269, e-mail: shimomura@chem.oit.ac.jp
}

A novel linker of 4-mercaptobenzoic acid (2) was developed for the synthesis of biphenyl derivatives. To evaluate 2 as a linker, 2 was coupled with aminomethyl resin (1) to give mercapto resin (3) as a solid support. The precursor of the target compounds, 4-bromobenzyl bromide was reacted with 3 through sulfide linkage to obtain the resin bound 4-bromobenzyl sulfide (4). Suzuki's cross-coupling reaction of the terminal bromide on the resin (4) was carried out with various aryl boronic acids to obtain biphenyl derivatives. The sulfide functionality was activated to sulfonium salt with $\mathrm{CH}_{3} \mathrm{I}-\mathrm{AgBF}_{4}$, resin 6 . Various nucleophiles were treated with the resin yielding the array of biphenyls.

Key words: solid phase organic synthesis, safety catch linker, sulfonium salt, Suzuki reaction

\section{INTRODUCTION}

Solid phase organic synthesis (SPOS) has become widely used for preparation of variety of combinatorial libraries. Among SPOS technology, linkers are generally used to keep intermediates bound to the resin support. Various types of linkers have been developed to adapt the fairly broad reaction conditions [1]. Recently a concept of safety-catch linker has been proposed for the synthesis of small molecules. Safety-catch linker shows the successive two cleaving steps; 1) convert the linker to cleavable form, and 2) actual release [2]. The main advantage of safety-catch linker is the stability during the reaction process until being activated, but once it is activated to cleavable form, the reaction for releasing the targets is smoothly proceeded even under mild conditions. Some safety-catch linker has been reported, whereas its use has some limitations for synthetic target [3]. We have briefly reported the possibility of the utilization of phenylthio group as a novel safety-catch linker for SPOS [4]. The sulfide functionality derived from phenylthio group can be activated to sulfonium salt. The treatment with amine nucleophile brings the objective compound in good yield and purity. Consequently, we attempted the utilization of phenylthio group for synthesis of biphenyl compounds as functional materials.

\section{EXPERIMENTAL}

\subsection{Measurements.}

${ }^{1} \mathrm{H}$ and ${ }^{13} \mathrm{C}$ NMR spectra were recorded in $\mathrm{CDCl}_{3}$ on a Varian Unity-300 spectrometer using tetramethylsilane (TMS) as an intemal standard. FT-IR spectra were obtained with a Shimadzu FT-IR 8200 spectrophotometer. Gas chromatography mass spectrometry (GC/MS) analyses were carried out on a Shimadzu QP-5000 equipped with GC-17A Gas chromatography using DB-1 (J\&W scientific, $30 \mathrm{~m} \times$ $0.25 \mathrm{~mm} \times 0.25 \mu \mathrm{m}$ column). Gas chromatography (GC) analyses were carried out on Shimadzu GC-17A instrument using Ultra Alloy-7 $(15 \mathrm{~m} \times 0.25 \mathrm{~mm} \times 0.25$ $\mu \mathrm{m}$ column).

\subsection{Materials.}

Aminomethyl polystyrene resin was prepared by reported method [5]. All of the chemicals were used without further purification.

2.3 Immobilization of 4-mercaptobenzoic acid (2) on aminomethyl resin (1)

To utilize the sulfide linkage, 4-mercaptobenzoic acid (2) was employed as a precursor of novel safety-catch linker for SPOS. To evaluate 2 as a linker, amidation of aminomethyl resin (1, loading: $1.2 \mathrm{mmol} / \mathrm{g})$ [5] with 2 was done to prepare a solid support. Typical condensation and the following reaction procedures are as following. The aminomethyl resin $1(0.24 \mathrm{mmol}, 0.20 \mathrm{~g})$ was treated with 2 $(0.12 \mathrm{~g}, 0.73 \mathrm{mmol})$ containing a drop of 4-dimethylaminopyridyne (DMAP) in DMF (4 $\mathrm{ml})$ by using 1-ethyl-3-(3'-dimethylaminopropyl)carbodiimide hydrochloride (WSC, $0.73 \mathrm{mmol}, 14 \mathrm{mg}$ ) and 1,3-diisopropylcarbodiimide (DIC, $0.073 \mathrm{mmol}$, $92 \mathrm{mg}$ ) as condensing agents at $\mathrm{rt}$ for $20 \mathrm{~h} \mathrm{[6].}$ The solution was removed by filtration, the derivatized resin was washed with $\mathrm{DMF}, \mathrm{H}_{2} \mathrm{O}$, THF, ethanol, and hexane, and the resin was dried 
Scheme 1 Synthesis of Biphenyl Derivatives by 4-Mercaptobenzoic Acid as a Safety-Catch Linker
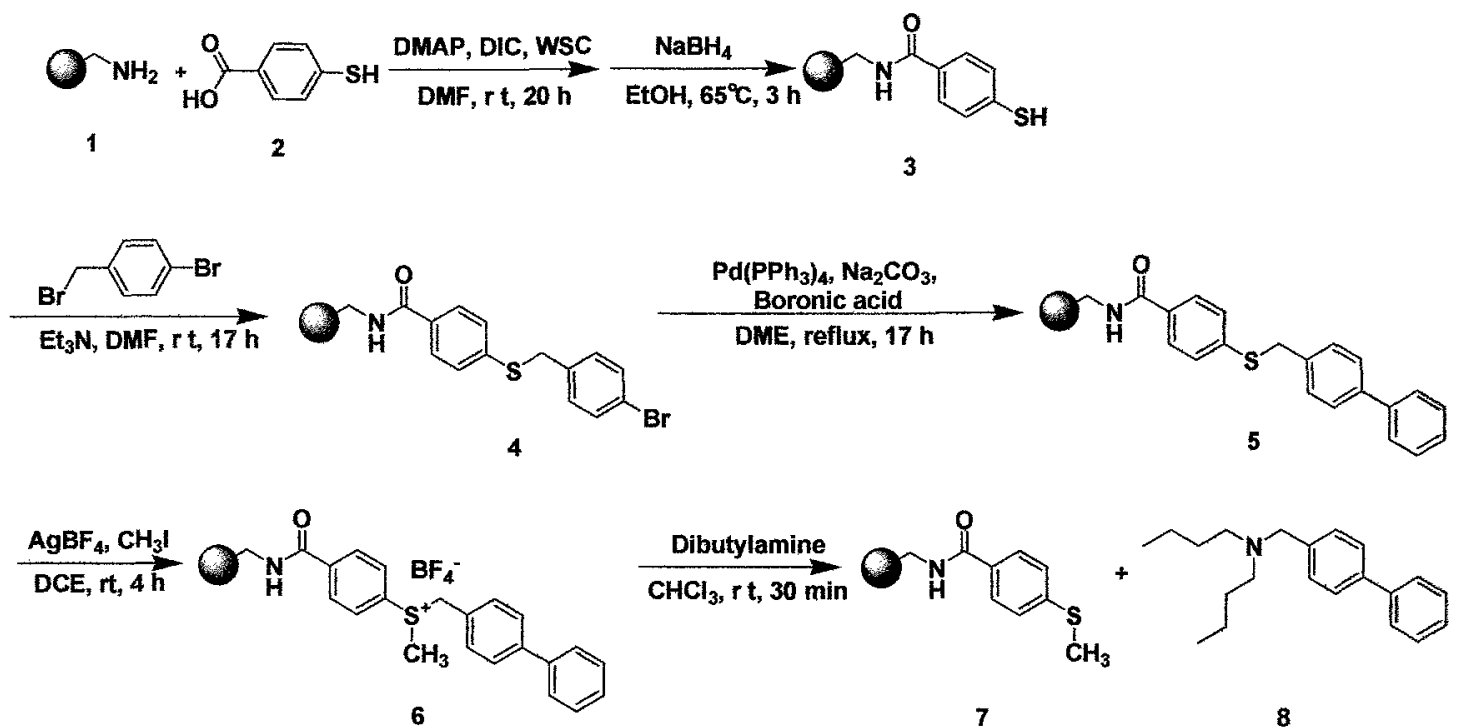

in vacuo (Scheme 1). To cleave the formation of disulfide bond, the resin was treated with $\mathrm{NaBH}_{4}(2.5 \mathrm{mmol}, 9.4 \mathrm{mg})$ in ethanol $(4 \mathrm{ml})$ at $65^{\circ} \mathrm{C}$ for $3 \mathrm{~h}$ [7]. The reaction mixture was poured into cold water $(50 \mathrm{ml})$. Hydrochloric acid $(1 \mathrm{~N})$ was added to the solution by $\mathrm{pH}=3$, the solution was stirred at $\mathrm{rt}$ for $30 \mathrm{~min}$. The treated resin was filtered off and washed with $\mathrm{H}_{2} \mathrm{O}$ and ethanol, and was dried in vacuo $(3$ in Scheme 1).

\subsection{Synthesis of biphenyls}

A typical procedure of the synthesis of biphenyls is shown as following. The precursor of the target biphenyl compounds, 4-bromobenzyl bromide $(0.74 \mathrm{mmol}, 0.19 \mathrm{~g})$ and $\mathrm{Et}_{3} \mathrm{~N}(0.74$ mmol, $75 \mathrm{mg}$ ) was added to 3 in DMF $(4 \mathrm{ml})$ at $\mathrm{rt}$ [8]. Shaking after $17 \mathrm{~h}$, the solution was removed by filtration, the derivatized resin was washed with DCE, acetone, ethanol, and hexane, and the resin was dried in vacuo. Aryl coupling by Suzuki reaction of the resin bound 4-bromobenzyl sulfide 4 with phenylboronic acid (0.74 mmol, $91 \mathrm{mg}$ ) was proceeded in DME (4 $\mathrm{ml})$ by using $\mathrm{Pd}\left(\mathrm{PPh}_{3}\right)_{4}(50 \mathrm{mmol}, 57 \mathrm{mg})$ and $\mathrm{Na}_{2} \mathrm{CO}_{3} \quad\left(2 \mathrm{~mol} / \mathrm{dm}^{3}, 1.0 \mathrm{ml}\right)$ under reflux condition for $17 \mathrm{~h}$ [9]. The solution was removed by filtration, the obtained resin was washed with DMF, $\mathrm{H}_{2} \mathrm{O}$, THF, ethanol, and hexane, and the resin $\mathbf{5}$ was dried in vacuo. To activate the sulfide linker to sulfonium salt, to a stirred 1,2-dichloroethane (DCE, $4 \mathrm{ml}$ ) of 5 and silver tetrafluoroborate $(0.74 \mathrm{mmol}, 0.14 \mathrm{~g})$ was added dropwise methyl iodide $(0.74 \mathrm{mmol}, 75$ $\mathrm{mg}$ ). After $4 \mathrm{~h}$ at $\mathrm{rt}$, the resin was separated by filtration and washed with DCE, acetone, ethanol, and hexane, and the resin was dried in vacuo. The sulfonium resin 6 obtained in chlroroform $(5$ ml) was added dropwise butylamine $(0.74 \mathrm{mmol}$, $96 \mathrm{mg}$ ) at $\mathrm{rt}$. After $30 \mathrm{~min}$, the solution was filtered off, and the filtrate was roughly evaporated. Ethyl acetate was added to the filtrate and washed with sat. $\mathrm{NaHCO}_{3}$ and brine, dried over $\mathrm{MgSO}_{4}$. The crude product was purified by column chromatography on silicagel column (ethyl acetate : hexane $=1: 50$ ) to give 8 in $74 \%$ yield [10]. Syntheses of other biphenyls were performed by similar procedure.

\section{RESULTS AND DISCUSSIONS}

\subsection{Synthesis of biphenyls by 2 as a Safety Catch Linker}

To evaluate 2 as a safety catch linker, 2 was immobilized on 1 by amidation using codensation reagents (Scheme 1). The progress of the reaction was confiremed by Kaizer qualitative analysis. To avoid the decrease of reaction efficiency by the formation of disulfide bonds, the derivatized resin was treated with $\mathrm{NaBH}_{4}$ for the reduction of disulfide to thiol [7]. Then the intermediate of the target compounds, 4-bromobenzyl bromide was reacted with thiol group of 3 to obtain the resin bound 4-bromobenzyl sulfide 4 . Cross-coupling by Suzuki reaction of 4 with phenylboronic acid was proceeded in DME using $\mathrm{Pd}\left(\mathrm{PPh}_{3}\right)_{4}$ as a catalyst to obtain the resin with the corresponding biphenyl unit 5 . The linker of sulfide was activated to sulfonium salt using $\mathrm{CH}_{3} \mathrm{I}-\mathrm{AgBF}_{4}$ as an alkylating reagent to obtain sulfonium resin 6 . The progress of the reaction was monitored by FT-IR spectrum watching the absorption band 
Table 1 Yields of biphenyls

Entry Boronic acid Yield (\%) Uncoupled product Yield (\%)

${ }^{a}$ Condition: 0.05 eq $\mathrm{Pd}\left(\mathrm{PPh}_{3}\right)_{4}, 2 \mathrm{M} \mathrm{Na}_{2} \mathrm{CO}_{3}, \mathrm{DME}$, reflux, $17 \mathrm{~h}$.

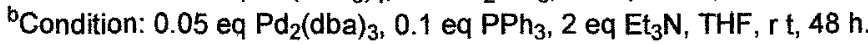

from $\mathrm{BF}_{4}^{-}$at $1024 \mathrm{~cm}^{-1}$.

The cleavage of the linker was performed using dibutylamine to obtain $N, N$-dibutyl-4phenylbenzylamine (8) in $74 \%$ isolated yield [11]. However the intermediate $N, N$-dibutyl-4-bromo- benzylamine that was not reacted during Suzuki reaction was determined in $20 \%$ isolated yield. This result shows that the efficiently of the linker functioned for detachment from resin support, because the total yields of $\mathbf{8}$ and $N, N$-dibutyl-4-

Table 2 Cleavage with various nucleophiles

\begin{tabular}{|c|c|c|c|c|}
\hline Entry & Nucleophile & Condition & Product & Yield ( \%) \\
\hline $1^{a}$ & $\mathrm{NaBr}$ & $\begin{array}{c}\text { THF } \\
r t, 2 h\end{array}$ & & 63 \\
\hline 2 & Nal & $\begin{array}{l}\text { THF } \\
r t, 2 h\end{array}$ & & 44 \\
\hline 3 & TBAB & $\begin{array}{c}\text { THF } \\
r t, 24 h\end{array}$ & B & 60 \\
\hline 4 & $\mathrm{NaBH}_{4}$ & $\begin{array}{c}\text { DME } \\
\text { reflux, } 8 \mathrm{~h}\end{array}$ & & 60 \\
\hline
\end{tabular}

aUncoupled product, i.e.; 4-bromobenzylbromide was obtained in $28 \%$ isolated yield. 
bromobenzylamine were $94 \%$

Various boronic acids were reacted by Suzuki reaction as shown in Table 1 . The reaction of entry 1-3 were proceeded with $\mathrm{Pd}\left(\mathrm{Ph}_{3}\right)_{4}$ as a catalyst under DME reflux $\left(85^{\circ} \mathrm{C}\right)$. Whereas the reaction of entry 4 and 5 , the yields of the products were low under those conditions. The reaction of entry 4 and 5 were proceeded with $\mathrm{Pd}_{2}(\mathrm{dba})_{3}$ as a catalyst in THF under ambient temperature. The electron donating group of methyl and methoxy might be affected strongly by the reaction conditions. The uncoupled bromo compounds were, however, obsereved to $19-27 \%$ isolated yields for all of the reactions.

\subsection{Synthesis of biphenyls cleaved with various nucleophiles}

The syntheses of biphenyl array using aryl sulfide linkage as a safety catch linker was shown above. Dibutylamine as a nucleophile was used for the detachment from resin support. If the cleavage could be used for various types of nucleophiles, the library compounds would have high diversity. Thus nucleophiles of halogenation (Entry 1-3) and of hydrogenation (Entry 4) were examined to the cleavage of 5 shown in Table 2. In the case of entry 1, 5 was treated with sodium bromide in THF at it for $2 \mathrm{~h}$ to obtain 4-phenylbenzyl bromide in $63 \%$ yield. Whereas the intermediate of 4-bromobenzylbromide was obtained in $28 \%$ yield. The 4-bromophenyl derivatives uncoupled were detected by ${ }^{\mathrm{b}} \mathrm{H}$-NMR and $\mathrm{GC}$ analyses in all cases. In entry 4, hydride acted to benzyl position and cleaved to 4-methylbiphenyl. The result shows the sulfide linkage functioned as a traceless linker.

\section{ACKNOWLEDGEMENT}

We are grateful to the Nanomaterials and Microdevice Research Centre (NMRC) of OIT for financial and instrumental supports.

\section{References}

[1] For example, see: (a) C. Gi1, K. Knepper, S. Bräse, "Polymeric Materials in Organic Synthesis and Catalysis" Edited by M. R. Buchmeiser, WILEY-VCH GmbH \& CO, KGaA (2003) pp. 139-164. (b) R. Warwass, "Combinatorial Chemistry" Edited by G, Jung, WILEY-VCH Verlag GmbH (1999) pp. 167-228. (c) B. A. Bunin, "The Combinatorial Index" Accademic Press, San Diego (1998) pp. 11-76.

[2] I.W. James Tetrahedron, 55, 4855-4946 (1999).

[3] For example, see: (a) G. W. Kenner, J. R. McDermott, R. C. Sheppard, Chem. Commun., 636-637 (1971). (b) J. B. Backes, A. A. Virgilio, J. A. Ellman, J. Am. Chem. Soc., 118, 3055-3056 (1996). (c) K. C. Nicolaou, S. Y. Cho, R.
Enderman, Chem. Eur. J., 7, 3798-3823 (2001). (d) K. C. Nicolaou, J. A. Prefferkorn, H. I. Mitchell, J. Am. Chem. Soc., 122, 9939-9954 (2000).

[4] O. Shimomura, K. Tayama, R. Nomura, Trans. Mater. Res. Soc. Jan., 30, 1073-1077 (2005).

[5] P. H. Toy, T. S. Reger, P. Garibey, J. C. Garno, J. A. Malikayil, G. Liu, K. D. Janda J. Comb.Chem, 3 (2001) 117-124.

[6] S. K. Shannon, M. J. Peacook, S. A. Kates, G. Barany, J. Comb. Chem., 5, 860-868 (2003).

[7] J. J. D'amico, J. Org. Chem., 26, 3436-3445 (1961).

[8] D. Font, M. Heras, J. M. Villalgordo, J. Comb. Chem., 5, 311-312 (2003).

[9] R. Frenette, R. W. Friesen, Tetrahedron Lett, 35, 9177-9180 (1994).

[10] The yield was calculated from the basis of the loading of 1.

[11] After the reaction of the solid support 7 would be reused by the reduction to mercapto resin 3 .

(Received December 10, 2006;Accepted February 19, 2007) 